\title{
A Meta-Heuristics Based Decision Support System for Optimal Crop Planning
}

\section{Oluwole Adekanmbi}

Department of Finance \& Information Management, Faculty of Accounting \& Informatics, Durban University of Technology, KwaZulu-Natal, South Africa, PO Box 101112, Scottsville, Pietermaritzburg 3201

Email: adekanmbioluwole@gmail.com

\author{
Paul Green \\ Department of Finance \& Information Management, Faculty of Accounting \& Informatics, \\ Durban University of Technology, KwaZulu-Natal, South Africa, \\ Email:paulg@dut.ac.za
}

Doi:10.5901/mjss.2014.v5n20p359

\begin{abstract}
This paper presents a meta-heuristic based decision support system to support farmers with optimal strategic decision making in the crop planning system. The analysis and modelling of crop planning decision making process are attractive for producing formalized knowledge on cropping plans in an agricultural farm. The formalization of the decision making process is generally becoming a crucial focal point for developing decision support systems that go beyond the limitation of formerly developed prescriptive approaches. The methodology of this research strikes a balance between mathematical formulations of crop planning problems and effective implementation of crop planning decision models. The new approach used to solve this problem is applicable to both medium and large scale farming; it is also integrated a systemic framework to build better decision support systems in agriculture.
\end{abstract}

Keywords: Crop planning; Decision support system; Meta-heuristic, Optimization, agriculture

\section{Introduction}

The agricultural sector is generally being faced with challenges of water use, soil erosion, and landscape design (Tong and Chen, 2002). Climate change (Richardson et al., 2009), market variation and regulation amendments for more sustainable resource planning compels farmers to perpetually adopt new farm practices. The adoption of these new farm practices aims to address issues relating to efficient use of resources and economic sustainability (Meynard et al., 2001). The farmer's acceptance of crop planning which is a key concept for designing an innovative cropping system is an illustration of the adoption of the new farm practices (Castellazzi et al., 2008). Furthermore, with the success rate of crop planning, leading researchers are requesting for new farm practices on which the developments of the new systems will be based (Van Notten et al., 2003).

Considering the difficulty of farming systems, model-based exploration tool is commonly utilized to complement the traditional empirical techniques for evaluating and designing new agricultural production systems. In spite of being faced with various challenges in transferring results to farmers (Stöckle et al., 2003), the suitability of a model-based techniques has been proved (Rounsevell et al., 2003). Crop selection and their land allocation are essential in crop planning decision making. These decisions focus on the complexity involved in the design of an innovative cropping system and selection of cropping plans which occur at different stages of crop production (Dury et al., 2012).

In crop production processes, crop planning decisions are certainly crucial with consequential influence on the long-run profitability and annual productivity of farms. A suitable crop planning model must satisfy several conflicting objectives and considering various factors/constraints and their interactions (Ganesan, 2006). Several models incorporated with designing a crop planning system have been built on cropping plan selections which could be the selection of either crop rotation or crop planning. The concept (crop rotation and crop planning) describes the crop planning decision problem in time and space respectively. Most of the models studied support the selection of one or more cropping plans with a specified objective but not all models were developed to support cropping decisions. In order to avoid any confusion, crop planning selection models have been utilized as a general term to designate the models. 
The crop planning decision model was used by the authors when referring to the decision-maker behaviour. Crop planning decisions are important in the utilization of land in a farming system and involve the selection of crops to be planted and their land allocation within a specific arable land (Aubry et al., 1998). These strategic decisions take place at the farm level, and are therefore part of the activities that occurs on the farm (Dury et al., 2012). A crop planning decision is the outcome of a decision making process where farmers consider several objectives and constraints. When farmers are making crop planning decisions, the primary concern is economics/profit. However, once the crops that will provide the highest net profit have been determined, they will often consider rotations, herbicide residues, weed quandaries and several other factors. This occurs as a result of the uncertainties that surrounds the decision-making process in that there may be various planting seasons, crop planning decision making does not only include a single decision but a continuous approach taking place all over the year (Johnson and Morehart, 2006).

\section{Literature Review}

\subsection{Reasons for modelling crop planning}

Given the large range of effects of the crop planning decisions at farm level, the designing of cropping plans using models is driven by many different motivations (Dury et al., 2010). Crop planning models are generally utilized to help agricultural policy makers, and farmers, in defining important strategies to evaluate landscape changes, allocate scarce resources efficiently. Several research was carried out using crop planning models and it was observed that these models share similar results when separately used within different research projects (Matthews et al., 2011) to meet different objectives (Alexandrov et al., 2011). Crop planning models were not only reviewed in terms of outcomes of projects but rather on how they affect the selection of cropping plans. Several methods have been summarized as two broad issues:

i. Crop planning selection for more improved resource allocation and more efficient resource utilization, and

ii. Crop planning decisions to evaluate large-scale changes (that is changes involving crop policy and landscape).

Even though, this distinction is important for presenting the existing works on crop planning, the researchers acknowledge that there is in fact strong relationship between the two issues.

\subsection{Crop planning problem formulation}

Crop planning models are usually developed to obtain better techniques of performing the resource allocation and land utilization. The techniques help to explore and design an alternate land-utilization system at several farm levels and may help in identifying best crop combinations and resource allocation choices (Dury et al., 2012). The primary goal of these models is to assist farmers and others in making strategic decisions while designing the farming systems. The modelling of a crop planning problem requires proper illustration and representation of the selection process in crop planning. The detailed level representation of the design process depends greatly on the objectives of the study. Formulation of crop planning problems is usually represented in models as a deterministic and a static resource allocation problem and is usually treated as the search of appropriate land for the best crop combination under some constraints.

Numerous studies indicate that the selection process in crop planning is directly obtained from the selection process in crop rotation which is mostly used as the main concept in the cropping system designs. The transition of crop rotations to crop planning models is frequently predicated on agricultural expert's knowledge using several crop sequence representations. Computed crop rotation (Bachinger and Zander, 2007) or recommended crop rotations (Stöckle et al., 2003) considers crop sequence requirements when selecting crop production plans (Haneveld and Stegeman, 2005). Several authors (Streit et al., 2003; Leteinturier et al., 2006) have demonstrated that annual flexibility in crop rotations improves the outcome of static crop rotation. Dogliotti et al. (2003) described flexible crop rotations to be of three types of:

i. fixed cyclic rotation,

ii. variable cyclic rotation and

iii. high variable rotation with less cyclic structure.

Several numerical formulation has been employed to represent flexible crop rotations in models, for instance Markov chains (Castellazzi et al., 2008) and network flow problems (Leteinturier et al., 2006; Detlefsen and Jensen, 2007). The benefit of incorporating flexible crop rotation into crop planning models is the ability to represent annual adjustment in cropping plans (Dury et al., 2012).

In crop planning related researches where selection processes are made on a yearly basis, the crop sequence requirements are either overlooked (Bergez et al., 2001) or integrated into the models as a parameter for reducing crop produce (Chabrier et al., 2007). Crop produce reduction parameters are either set by farm specialists (Stöckle et al., 
2003) or built on the regression exploration of historical information (Detlefsen, 2004), and as a result, selection process in crop planning is viewed as a single static decision of resource allocation (Dury et al., 2012). None of these methods consider a series of decisions in their problem formulation. Farmer's behaviour towards risk is always poor taking into account the uncertainties in some information (such as price and weather). The aspects of behavioural responses towards risk are studied in details in the field of agricultural economics (see: Hardaker, 2004; Olarinde et al., 2008).

\subsection{Crop planning problem resolution methods}

\subsubsection{Optimization}

Several techniques have been used to solve crop planning problems while satisfying the operational constraints. To a great extent, mathematical programming has been extensively utilized in this area (Glen, 1987; Feiring et al., 1998). Linear programming is the most popular optimization approach since Heady (1954) that has been employed in solving crop planning decision problems (Sarker et al., 1997; Adeyemo and Otieno, 2009). The linear programming model gained its popularity because of its simplicity and its ability of solving selection problems with various objectives (Leroy and Jacquin, 1991). Some problems associated with the use of this method take account of the difficulties in formulating the problem's objectives, constraints and deducing its results (Buick et al., 1992). The original linear programming framework has been extended in several application areas to reduce its limitations (Adeyemo and Otieno, 2009). Simple optimization approaches have been improved in several ways by searching for optimal solutions (Olarinde et al., 2008; Sadok et al., 2009), by incorporating fuzzy logic methods in order to ascertain the qualitative factors (Nevo et al., 1994), and decision's flexibility (Itoh et al., 2003) and random variables to address the uncertain factors (Sethi et al., 2006).

Multi-objective linear programming or Goal programming is an extension of linear programming models which is used to solve crop planning problem formulated as a multi-objective crop planning problem (Sahoo et al., 2006; Sharma and Jana, 2009). Based on the study, several objectives are clearly formulated with multi-dimensional function inside the crop planning models. For example, Sarker and Quaddus (2002) developed a goal programming model taking into account a wide range of farming situations, and allow optimization of environmental and/or profit outcomes. A multiobjective linear programming model was developed by Annetts and Audsley in 2002 for environmental farm planning (Annetts and Audsley, 2002). The multi-objective linear programming model was predicated on the crop planning model in Audsley (1993). The optimization tool provided an insight and helps to find out if a reduction in environmental impacts is achievable with minimal reduction in profit. Hayashi (2000) presented a comprehensive analysis of their application to agricultural resource management. Several multi-criteria methods have been employed in crop planning models by combining several objectives.

The main challenge of the multi-criteria techniques is in their ability to extract the objectives and elicit constraints, and thereafter assign weights to each objective using different weighting coefficient (Sumpsi et al., 1997). The linear programming framework is used not solely on almanac problem but for solving the crop planning problem. Haneveld and Stegeman (2005) utilize a standardized linear programming model integrated with a max-flow network representing the crop successions and predefined crop sequences that are not acceptable from an expert viewpoint are used as constraints. Detlefsen and Jensen (2007) used a network modelling technique in a slightly different way to model the problem of finding an optimal crop rotation for a given crop selection on a particular piece of land. Both approaches permit the application of flexible crop rotations in view of crop sequence requirements. Dogliotti et al. (2005) developed an interactive multiple-goal linear program named as "Farm Images" using mixed integer linear programming to solve the crop rotation problem. The approach was used to apportion production activities to a unit of farm lands of different soil quality, aimed at maximizing or minimizing socioeconomic and environmental objectives. The originality of the approach is that both the spatial heterogeneity of soil types of the farmland and the complex temporal interactions of rotation are considered in solving the crop planning problem.

Lately, evolutionary optimization algorithms have been employed in addressing multi-objective crop planning problems at farm level (Brunelli and von Lücken, 2009), at a nationwide level (Sarker and Ray, 2009) and provincial scale (DeVoil et al., 2006). The advantage of using evolutionary optimization algorithms is to get a set of solutions obtained from a set of Pareto optimal solution (Coello, 2009). Such algorithms seem particularly desirable for obtaining solutions for multi-objective optimization problems. Though, evolutionary optimization algorithms are quite different from linear programming methods, the formulation of the crop planning problem using an evolutionary optimization algorithm is closely related to the way crop planning problems are treated using other mathematical techniques. Louhichi et al. (2010) propose a nonlinear optimization approach predicated on positive mathematical programming (PMP). PMP employs both programming constraints and "positive" inferences from base-year crop allocations. 


\subsubsection{Expert applications}

Certain authors (Stone et al., 1992; Nevo et al., 1994) have indicated that applying only deterministic and quantifiable approaches is not sufficient to realize suitable crop planning due to the type of facts needed; as such facts is frequently uncertain, qualitative and incomplete. Nevo et al. (1994) incorporated an expert system technology with a traditional linear and mathematical programming technique to provide a solution to these setbacks. This method provides some consistency in search of space pruning, thereby decreasing the number of alternative allocations. These applications also involve a series of fine-tuning procedures that support the measurement of the influence of actual production conditions on the accrued income during a cropping period. The rules are predicated on expert's knowledge and are logically quantified using fuzzy logic techniques and uncertain processes using Bayesian theory. Stone et al. (1992) used artificial intelligence to solve the crop planning problem, not using traditional optimization methods (Dury et al., 2012).

\section{Crop Planning Mathematical Model}

This section presents the mathematical formulation of the optimal crop-mix planning problem investigated by this work. The optimal crop-mix planning model is designed to maximize total net-profit. The objective is to make an optimum use of the available limited resources in order to determine the land allocation for several competing crops required to be planted in a year. The mathematical model formulation has some similarities with those in Sarker et al., 1997; Sarker and Quaddus, 2002; Sarker and Ray, 2009; Chetty and Adewumi, 2014. Table 1 shows the similarities and dissimilarities of the crop planning mathematical formulation between the mentioned literatures and the current work.

Table 1: Objectives clearly formulated in crop planning models [个: maximization, $\downarrow$ : minimization].

\begin{tabular}{|c|c|c|c|c|c|c|}
\hline Author & Objective & \multicolumn{5}{|c|}{ Constraint } \\
\hline & & \multicolumn{4}{|c|}{ Similarities } & Dissimilarities \\
\hline Sarker and Quaddus (2002) & $\uparrow$ Total contribution & \multirow[b]{2}{*}{ Food demand } & \multirow[b]{2}{*}{ Land } & \multirow[b]{2}{*}{ Capital } & \multirow[b]{2}{*}{ Contingent } & \multirow[b]{2}{*}{ Area and import bound } \\
\hline Sarker and Ray (2009) & $\begin{array}{l}\uparrow \text { Total contribution } \\
\downarrow \text { Working capital }\end{array}$ & & & & & \\
\hline Current work & $\uparrow$ Net profit & $\begin{array}{l}\text { Economic demands } \\
\text { of crops }\end{array}$ & Land & Investment & & Labour \\
\hline Chetty and Adewumi (2014) & $\uparrow$ Total gross profits & & Land & & & Irrigation \\
\hline
\end{tabular}

The crop-mix planning model is designed for a large scale planning incorporated with the data collected from South African abstract of agricultural statistics (AAS, 2012). Refer to Adekanmbi and Olugbara, 2013, Adekanmbi et al., 2014a and Adekanmbi et al., 2014b for the mathematical formulation of the crop planning model.

\section{Framework of the System}

The decision support system has three elements; model, methodology, and system. The model comprises of series of parameter that help to structure the production process in agriculture. The methodology contains the specified algorithm that will work over the model and produce a better performance result. The system comprises of several software that assist the development of the decision support system using a meta-heuristic algorithm and the crop planning model. Having defined the available resources for planning, the data required for planning needed in the optimization model can be summarized as follows: 
Process Path requires knowing:

Knowledge of Categories of farm Operation

Identify the Problem Domain/Area in the Categories

Understand the Problem

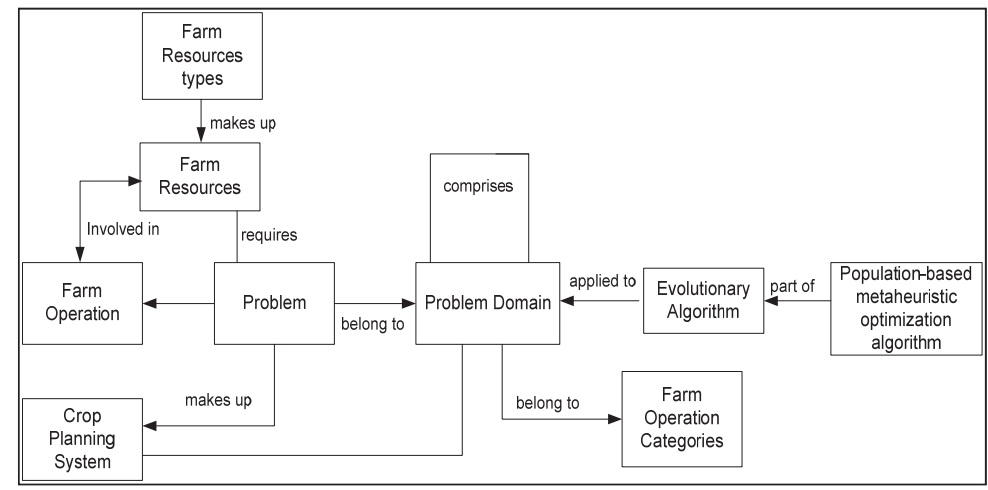

Figure 1: The Framework of the Crop Planning System

About the problem

Determine the Farm Resource used

About the Resources

Investment/Capital

Land

Cost

About each resource

Variable Cost

Fixed Cost

Figure 1 shows the general framework of the crop planning system. In this general framework, applying an optimization algorithm the crop planning model algorithm is the core element in the decision support system.

\section{Methodology}

As mentioned in the literature, several authors have used different optimization algorithms to solve a crop planning problem and gone as far as designing an expert application for a crop planning system. In this paper, the authors combined both crop planning resolution methods to solve a crop-mix planning problem. The formalization of the decision making process is generally becoming a crucial focal point for developing decision support systems that go beyond the limitation of formerly developed prescriptive approaches. The methodology of this research strikes a balance between mathematical formulations of crop planning problems and effective implementation of crop planning decision models. Different optimal crop-mix problems formulated in Adekanmbi and Olugbara, 2013, Adekanmbi et al., 2014a and Adekanmbi et al., 2014b were solved using a mathematical methodology of generalized differential evolution 3 algorithm to obtain globally optimal solutions.

Simulation experiments were conducted using the several state-of-art evolutionary algorithms to validate the performance of the generalized differential evolution 3 algorithm for solving optimal crop planning problems. The empirical results of those studies indicate that generalized differential evolution 3 algorithm is a viable alternative for optimal crop-mix planning decision. Based on the performance of the generalized differential evolution 3 algorithm in these literatures, the design of a decision support system incorporated with an evolutionary algorithm was realized which promises to assist farmers and decision-makers within the agricultural sector to make optimal decisions pertaining to crop planning. Readers interested in the generalized differential evolution 3 algorithm should refer to the texts - Kukkonen and Lampinen, 2005; Kukkonen and Lampinen, 2006; Kukkonen and Lampinen, 2008; Kukkonen and Lampinen, 2009. 


\section{Implementation of Optimal Crop Planning System}

This section presents the implementation of the decision support system called CPLANNER to provide proof-of-concept through a real life model implementation. The implementation demonstrates relevance in the farm management domain. The primary objective of the research was to develop a decision support tool for assisting local farmers to make optimal strategic decisions in crop farming system. The proposed system should therefore assist local farmer to make the optimal strategic decision in crop planning. The varied operation provided by the system could be used for crop planning related operations such as land allocation, and crop selection to allow informed decision making. The prototype system provides basic related functions such as capturing crop information, managing the information on crop combination. CPLANNER involves two actors: primary business actor and secondary actor. The primary business actor is the stakeholder who primarily benefits from the execution of the processes by receiving something of measurable or observable value. The secondary actor is the stakeholder that helps the system to fulfill its objectives. Figures 2 indicate the primary business actor as the farmer and the secondary actor as the administrator. Figure 2 shows the activity diagram for the overall process in the CPLANNER system which is logically divided into three main phrases, registration, initialization and displaying of the optimal solution.

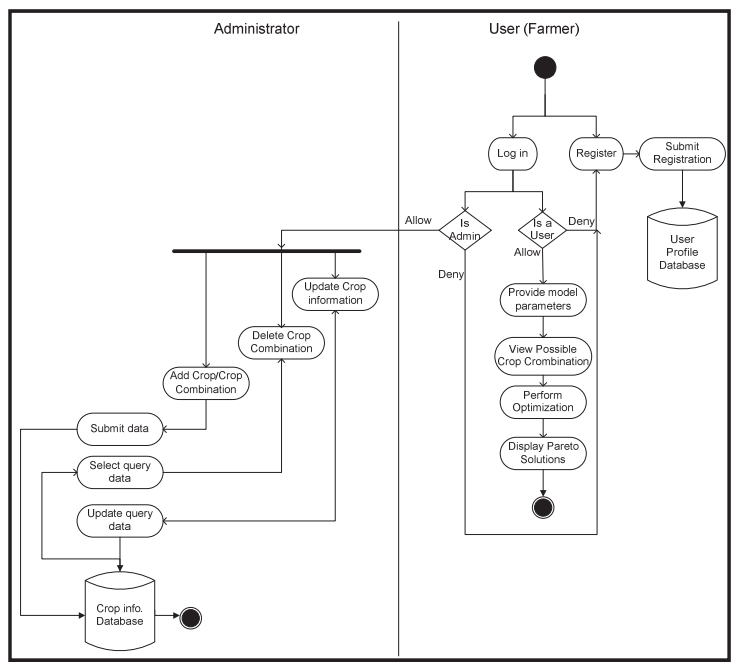

Figure 2: CPLANNER system process

A registration process begins when a user successfully logs onto the system and ends when the user submits registrations and quits the system. Similarly, the optimization process begin when the user requests for a cropping pattern based on the selected crops and ends when the user obtain the cropping pattern with the best net profit and quits the system. The data recorded are stored in the database for easily accessible for future retrieval, analysis and use in various planning and decision making processes. The prototype system is designed in way that it is relatively easy to use and simple to accommodate basic users with very little literacy levels to skilled users. The user interaction modality is facilitated by a web portal interface as the system was implemented using ASP.NET programming language in VISUALSTUDIO version 2012 on an HP PC with Pentium dual core processor having 2.30GHz clock speed and 4GB of RAM.

\subsection{How the CPLANNER works}

The CPLANNER decision support system is tested with a situation where household farmer like to invest 50000 South African Rands in the land mass of 3 hectare. 


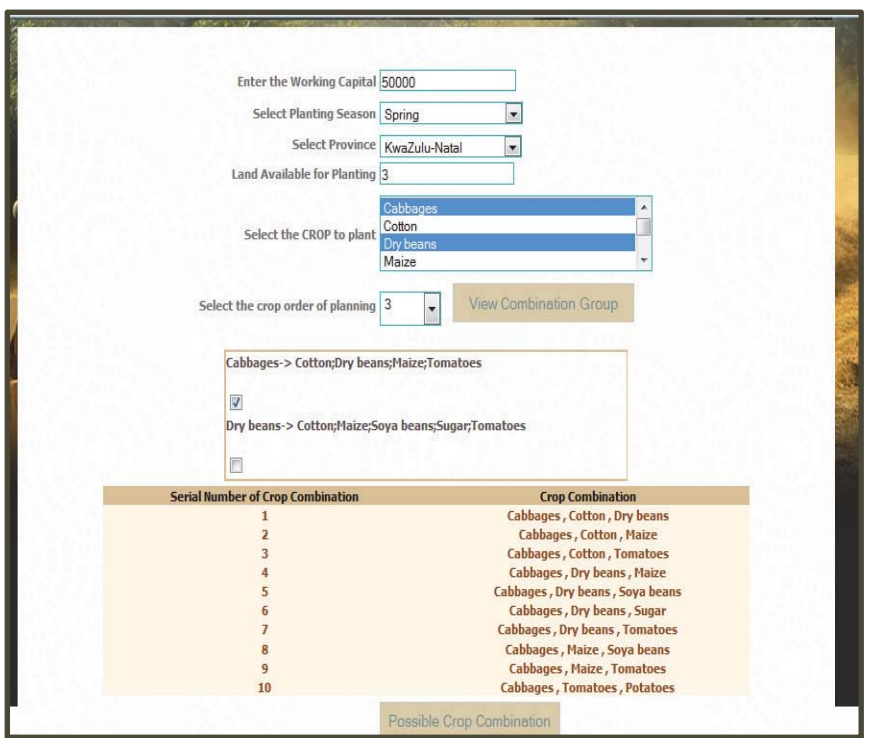

Figure 3: The Screen shot of the process page of the CPLANNER decision support system

The farmer logs onto the system and registers, and then chooses to plant crops that could be planted with cotton and maize in a tri-cropped land i.e. such that the crop combination should be of order 3 . The user then enters all his requirements, then click on the button (view combination group) to view the crop combination group, the crop combination groups consist of crops that could be planted with the selected crops (cabbage, dry beans). To view the number of possible crop combination that could be obtained, the farmer selects any of the crop combination group of his choice and click on the button (possible crop combination). Figure 3 shows the screen shot of the whole process.

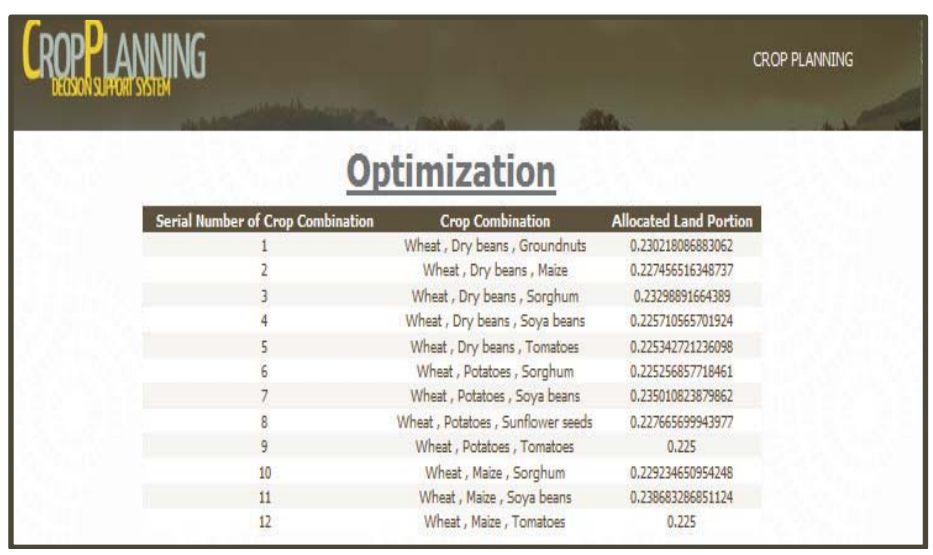

Figure 4: CPLANNER land allocation results

The system allocated a land portion to each crop combination - working with the scenario where the farmer decided to choose single combination groups; the system produced the result in Figure 4. Finally, Table 2 shows the best result of the optimization process while maximizing net profit 
Table 2: Optimization Process Output

\begin{tabular}{cc} 
Net-Profit (ZAR) & Total Land Utilization (ha) \\
\hline 4441.11598464471 & 2.74756812616138 \\
\hline
\end{tabular}

\section{Conclusion}

This work suggests that a meta-heuristic based decision support system is a useful tool for optimal crop-mix planning decision support. The results obtained from developing the decision support system have unique significance in managing land plot and making strategic crop planning decisions. With regard to land allocation, a group of farmer who tested the system was pleased to use a tool that will undertake the planning of crop every year. The approach combines local farming with information technology to optimize crop production, support efficient planning and help farmers determine the possible combination of crops to plant on the same planting land year by year. The most importance features of the system appreciated by the farmers are the graphical user interface (GUI) for both entering the data and outputting the report generated by the decision support system.

\section{References}

AAS (Abstract of Agricultural Statistics). 2012. Directorate Agricultural Information. National Department of Agriculture, Pretoria.

Adekanmbi, O., Olugbara, O. and Adeyemo, J. 2014a. An Investigation of Generalized Differential Evolution Metaheuristic for Multiobjective Optimal Crop-Mix Planning Decision. The Scientific World Journal.

Adekanmbi, O. A. and Olugbara, O. O. 2013. Optimal crop planning decision support for subsistence farmers. In: Proceedings of INTERACT 2013. Cape town, South Africa,

Adekanmbi, O. A., Olugbara, O. O. and Adeyemo, J. 2014b. A Comparative study of State-of-the-Art Evolutionary Multi-Objective Algorithms for Optimal Crop-mix planning. International Journal of Agricultural Science and Technology (IJAST), 2 (1), 8-16.

Adeyemo, J. and Otieno, F. 2009. Optimizing planting areas using differential evolution (DE) and linear programming (LP). Int. J. Phys. Sci, 4 (4), 212-220.

Alexandrov, G., Ames, D., Bellocchi, G., Bruen, M., Crout, N., Erechtchoukova, M., Hildebrandt, A., Hoffman, F., Jackisch, C. and Khaiter, P. 2011. Technical assessment and evaluation of environmental models and software: Letter to the Editor. Environmental Modelling \& Software, 26 (3), 328-336.

Annetts, J. and Audsley, E. 2002. Multiple objective linear programming for environmental farm planning. Journal of the Operational Research Society, 53 (9), 933-943.

Aubry, C., Biarnes, A., Maxime, F. and Papy, F. 1998. Modélisation de l'organisation technique de la production dans l'entreprise agricole: la constitution de systèmes de culture du Bassin parisien. Etud Rech Syst Agraires Dév, 31, $25-43$.

Audsley, E. 1993. Labour, machinery and cropping planning. In: Proceedings of Farm planning. Labour and labour conditions. Computers in agricultural management (edited by Annevelink, E., Oving, RK and Vos, HW). Proceedings XXV CIOSTACIGR V Congress Wageningen, Netherlands. Wageningen Pers. 83-88

Bachinger, J. and Zander, P. 2007. ROTOR, a tool for generating and evaluating crop rotations for organic farming systems. European Journal of Agronomy, 26 (2), 130-143.

Bergez, J., Debaeke, P., Deumier, J.-M., Lacroix, B., Leenhardt, D., Leroy, P. and Wallach, D. 2001. MODERATO: an object-oriented decision tool for designing maize irrigation schedules. Ecological Modelling, 137 (1), 43-60.

Brunelli, R. and von Lücken, C. 2009. Optimal Crops Selection using Multiobjective Evolutionary Algorithms. Al Magazine, 30 (2), 96.

Buick, R. D., Stone, N. D., Scheckler, R. K. and Roach, J. W. 1992. Crops: a whole-farm crop rotation planning system to implement sustainable agriculture. Al applications, 6.

Castellazzi, M., Wood, G., Burgess, P. J., Morris, J., Conrad, K. and Perry, J. 2008. A systematic representation of crop rotations. Agricultural Systems, 97 (1), 26-33.

Chabrier, P., Garcia, F., Martin-Clouaire, R., Quesnel, G. and Raynal, H. 2007. Toward a simulation modeling platform for studying cropping systems management: the record project. In: Proceedings of International Congress on Modelling and Simulation, MODSIM. Citeseer, 10-13

Chetty, S. and Adewumi, A. 2014. Comparison of Swarm Intelligence Meta-heuristics for the Annual Crop Planning Problem. IEEE Transactions on Evolutionary Computation, 18 (2), 258 - 268.

Coello, C. A. C. 2009. Evolutionary multi-objective optimization: some current research trends and topics that remain to be explored. Frontiers of Computer Science in China, 3 (1), 18-30.

Detlefsen, N. 2004. Crop rotation modelling. In: Proceedings of Proceedings of the EWDA-04 European workshop for decision problems in agriculture and natural resources. Silsoe Research Institute, England. 5-14

Detlefsen, N. and Jensen, A. L. 2007. Modelling optimal crop sequences using network flows. Agricultural Systems, 94 (2), 566-572.

DeVoil, P., Rossing, W. A. and Hammer, G. 2006. Exploring profit-sustainability trade-offs in cropping systems using evolutionary algorithms. Environmental Modelling \& Software, 21 (9), 1368-1374. 
Dogliotti, S., Rossing, W. and Van Ittersum, M. 2003. ROTAT, a tool for systematically generating crop rotations. European Journal of Agronomy, 19 (2), 239-250.

Dogliotti, S., Van Ittersum, M. and Rossing, W. 2005. A method for exploring sustainable development options at farm scale: a case study for vegetable farms in South Uruguay. Agricultural Systems, 86 (1), 29-51.

Dury, Garcia, F., Reynaud, A., Therond, O. and Bergez, J. 2010. Modelling the Complexity of the Cropping Plan Decision-making". In: Proceedings of International Environmental Modelling and Software Society (iEMSs), 2010 International Congress on Environmental Modelling and Software, Modelling for Environment's Sake, Fifth Biennial Meeting, Ottawa, Canada.

Dury, Schaller, N., Garcia, F., Reynaud, A. and Bergez, J. E. 2012. Models to support cropping plan and crop rotation decisions. A review. Agronomy for Sustainable Development, 32 (2), 567-580.

Feiring, B., Sastri, T. and Sim, L. 1998. A stochastic programming model for water resource planning. Mathematical and Computer Modelling, 27 (3), 1-7.

Ganesan, V. 2006. Decision Support System "Crop-9-DSS" for Identified Crops. In: Proceedings of 10th International.

Glen, J. J. 1987. Mathematical models in farm planning: A survey. Operations Research, 35 (5), 641-666.

Haneveld, W. and Stegeman, A. W. 2005. Crop succession requirements in agricultural production planning. European Journal of Operational Research, 166 (2), 406-429.

Hardaker, J. B. 2004. Coping with risk in agriculture [electronic resource]. CABI.

Hayashi, K. 2000. Multicriteria analysis for agricultural resource management: a critical survey and future perspectives. European Journal of Operational Research, 122 (2), 486-500.

Heady, E. O. 1954. Simplified presentation and logical aspects of linear programming technique. Journal of Farm Economics, 36 (5), 1035-1048.

Itoh, T., Ishii, H. and Nanseki, T. 2003. A model of crop planning under uncertainty in agricultural management. International Journal of Production Economics, 81, 555-558.

Johnson, J. and Morehart, M. 2006. Farm Business Management. Agricultural Resources and Environmental Indicators: 109.

Kukkonen, S. and Lampinen, J. 2005. GDE3: The third evolution step of generalized differential evolution. In: Proceedings of Evolutionary Computation, 2005. The 2005 IEEE Congress on. IEEE, 443-450

Kukkonen, S. and Lampinen, J. 2006. Constrained real-parameter optimization with generalized differential evolution. In: Proceedings of Evolutionary Computation, 2006. CEC 2006. IEEE Congress on. IEEE, 207-214

Kukkonen, S. and Lampinen, J. 2008. Generalized Differential Evolution for General Non-Linear Optimization. In: COMPSTAT 2008. Springer, 459-471.

Kukkonen, S. and Lampinen, J. 2009. Performance assessment of generalized differential evolution 3 with a given set of constrained multi-objective test problems. In: Proceedings of Evolutionary Computation, 2009. CEC'09. IEEE Congress on. IEEE, 1943-1950

Leroy, P. and Jacquin, C. 1991. LORA: a decision support system for the choice of crops on the irrigable area of a farm. Decision Support Systems, IFORSSPC1.

Leteinturier, B., Herman, J., Longueville, F. d., Quintin, L. and Oger, R. 2006. Adaptation of a crop sequence indicator based on a land parcel management system. Agriculture, Ecosystems \& Environment, 112 (4), 324-334.

Louhichi, K., Kanellopoulos, A., Janssen, S., Flichman, G., Blanco, M., Hengsdijk, H., Heckelei, T., Berentsen, P., Lansink, A. O. and Ittersum, M. V. 2010. FSSIM, a bio-economic farm model for simulating the response of EU farming systems to agricultural and environmental policies. Agricultural Systems, 103 (8), 585-597.

Matthews, K., Rivington, M., Blackstock, K., McCrum, G., Buchan, K. and Miller, D. 2011. Raising the bar?-The challenges of evaluating the outcomes of environmental modelling and software. Environmental Modelling \& Software, 26 (3), 247-257.

Meynard, J.-M., Dore, T. and Habib, R. 2001. L'évaluation et la conception de systèmes de culture pour une agriculture durable. Comptes rendus de l'Académie d'agriculture de France, 87 (4), 223-236.

Nevo, A., Oad, R. and Podmore, T. H. 1994. An integrated expert system for optimal crop planning. Agricultural Systems, 45 (1), $73-92$.

Olarinde, L., Manyong, V. and Okoruwa, V. 2008. Analyzing optimum and alternative farm plans for risk averse grain crop farmers in Kaduna state, northern, Nigeria. World Journal of Agricultural Sciences, 4, 28-35.

Richardson, K., Steffen, W., Schellnhuber, H. J., Alcamo, J., Barker, T., Kammen, D. M., Leemans, R., Liverman, D., Munasinghe, M. and Osman-Elasha, B. 2009. Synthesis report. In: Proceedings of Climate Change Congress Global Risks, Challenges \& Decisions. Kopenhagen. 12

Rounsevell, M., Annetts, J., Audsley, E., Mayr, T. and Reginster, I. 2003. Modelling the spatial distribution of agricultural land use at the regional scale. Agriculture, Ecosystems \& Environment, 95 (2), 465-479.

Sadok, W., Angevin, F., Bergez, J.-É., Bockstaller, C., Colomb, B., Guichard, L., Reau, R. and Doré, T. 2009. Ex ante Assessment of the Sustainability of Alternative Cropping Systems: Implications for Using Multi-criteria Decision-Aid Methods-A Review. In: Sustainable Agriculture. Springer, 753-767.

Sahoo, B., Lohani, A. K. and Sahu, R. K. 2006. Fuzzy multiobjective and linear programming based management models for optimal land-water-crop system planning. Water resources management, 20 (6), 931-948.

Sarker and Quaddus, M. 2002. Modelling a nationwide crop planning problem using a multiple criteria decision making tool. Computers \& industrial engineering, 42 (2), 541-553.

Sarker and Ray, T. 2009. An improved evolutionary algorithm for solving multi-objective crop planning models. Computers and electronics in agriculture, 68 (2), 191-199.

Sarker, Talukdar, S. and Haque, A. 1997. Determination of optimum crop mix for crop cultivation in Bangladesh. Applied Mathematical 
Modelling, 21 (10), 621-632.

Sethi, L. N., Panda, S. N. and Nayak, M. K. 2006. Optimal crop planning and water resources allocation in a coastal groundwater basin, Orissa, India. Agricultural Water Management, 83 (3), 209-220.

Sharma, D. K. and Jana, R. 2009. Fuzzy goal programming based genetic algorithm approach to nutrient management for rice crop planning. International Journal of Production Economics, 121 (1), 224-232.

Stöckle, C. O., Donatelli, M. and Nelson, R. 2003. CropSyst, a cropping systems simulation model. European Journal of Agronomy, 18 (3), 289-307

Stone, N. D., Buick, R. D., Roach, J. W., Scheckler, R. K. and Rupani, R. 1992. The planning problem in agriculture: Farm-level crop rotation planning as an example. Al applications in natural resource management, 6.

Streit, B., Rieger, S., Stamp, P. and Richner, W. 2003. Weed populations in winter wheat as affected by crop sequence, intensity of tillage and time of herbicide application in a cool and humid climate. Weed Research, 43 (1), 20-32.

Sumpsi, J., Amador, F. and Romero, C. 1997. On farmers' objectives: A multi-criteria approach. European Journal of Operational Research, 96 (1), 64-71.

Tong, S. T. and Chen, W. 2002. Modeling the relationship between land use and surface water quality. Journal of environmental management, 66 (4), 377-393.

Van Notten, P. W., Rotmans, J., van Asselt, M. and Rothman, D. S. 2003. An updated scenario typology. Futures, 35 (5), $423-443$. 